\title{
Towards a conceptual foundation for documenting tangible and intangible elements of a cultural object
}

\author{
Nicola Carboni, Livio de Luca \\ UMR 3495 MAP CNRS/MCC, Marseille, France
}

A r icle info

Keywords:

Cultural heritage

Intangible heritage

CIDOC-CRM

Iconography

Ontology

Semantics

\begin{abstract}
A b s t r a c t
This article analyses the concept of intangible/tangible heritage from a documentation perspective, investigating the theoretical framework developed within the various branches of the cultural heritage studies and providing a clear perspective, as well as an alignment, of the various approaches and requirements. The focus provided highlights the prospect of developing a conceptual foundation that would cover the documentation of the tangible and intangible elements of a cultural object. The theoretical assumptions are then analysed from an ontological perspective, and tested using CIDOC-CRM, developing a series of representative mappings, including information about the material, spatial and symbolic elements of a scene in a narrative cycle painted in the narthex of a byzantine church in Cyprus. The result is a formalisation of a set of requirements and a documentation paradigm which help record the tangible and intangible elements of an heritage asset.
\end{abstract}

\section{Introduction}

In the second half of 20th century, a series of new studies began to question the nature of cultural heritage, focusing on its identity and its transmission mechanism (Bouchenaki, 2003; Kurin, 2004). What was called at the time folklore or popular culture became the subject of a philosophical and legislative investigation, in an attempt to include it in the current institutional heritage preservation and documentation practices. The great efforts that have been made over the last 50 years, culminated in 2003 when UNESCO, during the "Convention for the Safeguarding of Intangible Cultural Heritage” (UNESCO, 2003) formulated a legislative framework for preserving the so-called intangible heritage. Precedent to the convention was the creation of an index for the registration of the intangible heritage, called in 2001 "Masterpieces of the Oral and Intangible Heritage of Humanity" (UNESCO, 2006) and later known as the UNESCO Intangible Cultural Heritage Lists.

Unfortunately, the creation of the list, not only cemented the idea of a tangible-intangible dichotomy but produced an indexing and cataloguing strategy based on such a conception. Adapting and building documentation schemes around this formula has generated a series of issues, mostly in regards to the formalisation of contextual information and the symbolic meanings, which are not yet resolved.

This article aims to create the conceptual foundation for an information structure that would resolve the problems inadvertently generated by this dichotomous view by proving that the recorded data in the tangible and intangible domain relate to the same group of entities and can in principle be registered under the same semantic framework.

In order to ground the necessary theoretical stance to support this position, section two analyses the tangible/intangible elements that are taken into consideration. Next, Section 3 evaluates the previous literature on these topics, focusing on examples of describing intangible elements using formal systems. The latter half of the article is divided in two parts. Section 4.1 summarizes the ontological requirements and choices available from a documentation perspective for formalizing these elements, while Section 4.2 is dedicated to the analysis of the possible documentation path for the description of the conceptual elements present in a Byzantine icon, and the connections between such elements and a bigger framework of practices.

\section{Analysis of the problem}

\subsection{Tangible and intangible heritage: a theoretical perspective}

The declaration of an intangible heritage as the compliment of tangible heritage it has a respectable aim, but also the unfortunate effect of separating the focus of documentation over two apparently quite different and distinct objects, the item and the act. In so doing, the rich network of relationships that exist between the two are artificially bifurcated and thereby obscured.

But, as Hodder (2012) has recently argued, a cultural object has always to be seen as the outcome of the relationships between itself and 
the world around it, such as between an object and another object, between a human and an object, and between the environment and the object. For example, in case of human production, an artefact is the result of the interaction between a person, a set of tools and a technique/strategy, all of which are involved in producing an item during an act. Starting only from these elements, we can easily see how an object is the result of a series of interactions between other physical entities, and it heavily relies on intangible elements, such as a specific techniques and a particular social arena, for its identity. Additionally, the significance of an object is always actively constructed within a context and, consequently, its representation is subjective and a consequence of a knowledge exchange dynamic.

Objects are, therefore, strictly connected to the diverse aspects of social organisation, culture, systems of thought, or actions (Lemonnier, 2013 , 2012), shaping the normative behaviour of a group, reflecting in themselves the identity of a social landscape (Miller, 2010, 2005), and acting as communication devices. The meaning can be encoded in the artefact using a basic cognitive process (Fauconnier and Turner, 2003) which constructs a reality throughout the projection of a conceptual model into a new mental space that blends the properties of the two "parents" into a new representation anchored in a material object. The result of the conceptual blending is usually used in a social arena to

define a symbolic meaning of its own reality (Hutchins, 2005). For such reasons context and object always exist in a circular relationship (Bal and Bryson, 1991).

Objects should thus be seen as material anchors shaping the normative behaviour and agency of performative actions in a social space, helping to generate new dispositions (as in Bourdieu (Grenfell, 2008)) throughout differentiation in practices, which would themselves later be responsible for associating new meanings to objects or techniques (Lemonnier, 2013; Mauss, 1973). Therefore, in face of a false bifurcation of heritage into two separate halves, we must agree that "intangible culture makes the background of tangible cultural property" (Ito, 2003) and "tangible heritage, without intangible heritage, is a mere husk or inert matter" (Kirshenblatt Gimblett, 2004).

The documentation of events and practices is seen by UNESCO to fall within the domain of intangible heritage. UNESCO classifies these kinds of act as: knowledge and practices, oral tradition and expression, performing arts, social practices, traditional craftsmanship. What is clearly the common denominator in all of the above is that they are types of performance. As highlighted by Taylor (2003) performances include a broad range of cultural behaviours (including phenomena like dance, civic obedience etc.) and are the key factor for transmitting the

repertoire, the embodied knowledge of a specific social arena. Performance requires tangible objects, for gaining meaning and helping understand the act throughout their use.

The case of traditional craftsmanship is, to some degree, different from the other practices, because the stress is laid on recording the procedural knowledge used by an artisan. However, instead of recording the knowledge used during the craft, as well as the social significance of the resulting object, what is actually described is only a specific type of performative act, documented just as a procedure/ technique. Nevertheless, there is a documented link between certain everyday objects, the technique used for their creation, and the social landscape of reference (Lemonnier, 2012) that should always be clearly mentioned when recording such phenomena.

Some quick examples of the construction of meaning and on the complexity of the relationships between tangible and intangible heritage can be drawn from history of art and literature.

Western art is a perfect example, because it is built on a symbolism that allows us to recognise a particular emotion in play in the painting/ sculpture. The symbolism of its motifs (the colour used or the type of poses are typical examples) can be deployed consciously or unconsciously; it is, regardless, the product of the habitus that produces it. Consequently, the transmission of this conventions, considered a typical intangible expression, passes along with the transmission of a physical object. Moreover, the transmission itself is mediated by schema and vocabularies of the current social space, and therefore the product of the painting process is not a mere reconstruction of reality (as believed by the naturalists), but always a mediated view. The mediation comes from the techniques used to augment the recognition of reality that is a significant base of the pictorial arts. Usually such kinds of pictorial vocabulary arise from the teaching of the masters in readymade memorisable codes that help both to transmit as well as to define a style (Gombrich, 1994). The use of a set of vocabularies for the depiction of a character/scene is not limited only to the pictorial arts. In literature such phenomena are widely studied taking into considera-tion not only the motifs (Uther, 2004) used within the stories, but also the possible structure of the interactions within a certain narrative form (Propp, 1971). The recognised units of analysis (both motifs or structural elements) are then, like it happens in the pictorial art, conveyed to a user, who is able to recognise them because the schema embedded in his habitus helps him understand the symbolic power of gestures, phrases etc.

Such considerations make clear the necessity not only not to fall into a false dualism in the documentation of heritage, but also emphasize the fact that the tangible and intangible elements of a cultural object or practice are only properly addressed when they are described and preserved together.

\subsection{Tangible and intangible heritage: an information perspective}

The cataloguing, organisation and archiving of the information related to cultural objects and practice is constructed throughout the registration of different media items (photo, video, text or 3D reconstruction), which function as an anchor and representative in a digital space of the original object/phenomena. The data is generally structured by the use of metadata (Baca et al., 2006; Lubas et al., 2013), which serves as an access point for retrieving information about a digital object. The result is generally a series of flattened object-centric descriptors which, even if they clearly somehow relate to the same phenomena, fail to fully describe it in relation to its context, providing to the final users only a partial account of its complexity. Moreover, the current approaches in the discipline are deeply informed by, and therefore reproduce, the dichotomy between the tangible and intangible heritage. This results in a failure to create the necessary semantic links between the elements, limiting the understanding conveyed of the interrelationship between performative act, objects and their meaning in a specific context. Addressing the defects of such structures will require, in the first place, dropping the object-centric approach and making a shift towards an event/process-centric repre-sentation (Kettula and Hyvönen, 2012), while enforcing the use of semantic systems able to record the relationships between the de-scribed entities.

Moreover, as a basic requirement, cultural heritage discourse has always to be considered as shared between different actors, who can themselves understand the specific activity/object quite differently from each other, assigning it different meanings on the base of their social landscape. In this context, it is of paramount importance to fix the recorded assertions within a shared information structure, like a formal ontology, which would help in anchoring, sharing and classify-ing the recorded propositions. Using a well-founded formal ontology (Guarino, 1998) would allow the assignment of the data attributes asserted by various actors/social groups, providing the shared ground for a group of specialists to enrich and compare with each other's documentation.

Such a shift from flat documentation to an ontologically founded documentation structures provide the prerequisite to the unification of different discourses into a flexible system, able to fully represent the richness of the disciplines involved in the analysis of the object and thus met the challenge of describing objects/practices in their full meaning. Moreover, this method gives the possibility to transforming 
the recorded assertions into a series of logical statements that can be interpreted by a reasoner, which can infer implicit knowledge from the original records and augment them, in order to represent and reveal a richer network of relationships between the elements.

\subsection{General point of view}

The above arguments demonstrate that the differences between tangible and intangible are only a recent, accidental social construct, and do not represent a genuine dichotomy. This dichotomy is, consequently, ineffective for creating holistic documentation. The latter goal is better achieved by placing focus on the construction of meaning, and the living relations between performances and objects, presenting a full account of the relationships between person-object-event.

In order to make these connections explicit, and provide a guide for documentalist, a set of parameters and paradigms need to be formalised and explained.

\section{Literature review}

While the nature of 'intangible heritage' has been extensively studied, not enough attention has been allocated to the formalisation of its documentation practice as a whole. We have found, in fact, only three attempts to formalise and publish a metadata set for the cataloguing this specific type of heritage.

(Istituto Centrale per il Catalogo E La Documentazione, 2006; Kim and Kim, 2013; Viudez, 2010).

The rest of the studies approach the subject on a case-by-case perspective, without creating a real harmonisation between theory and practice, and relying on a wide range of heterogeneous methodologies and perspectives.

Mallik et al. $(2013,2011)$ focused on the annotation of semantic features in MPEG video about Indian dance. Their approach considers destructuring the studied activity into retrievable units of analysis, enriching them with the conceptual significance of the poses or with some multimedia objects.

Amin et al. (2012, 2011) outlined the process for creating a metamodel useful for archiving intangible heritage. Unlike other research, they recognised several actions that can be categorised under the umbrella term of 'intangible', instead of focusing only on feature of the subject of the discourse. Nevertheless, during their analysis, they split the description parameters into extra and intra cultural elements. In our view such a stance is not in line with the cohesive view of culture outlined in Section 2. Furthermore, their conceptual description is lacking a detailed semantic investigation.

$\mathrm{Hu}$ et al. (2014) and Tan et al. (2008) used CRM as framework for describing respectively the Pang Wang and the Dragon Boat Festival in China and provided an analysis for mapping their data to CIDOC-CRM. Unfortunately, their description does not make any assertion about the significance of the festival or define any conceptual elements that characterise it.

Another analysis of the subject was carried out by De Luca et al. (2013) during the analysis and documentation of the tomb of emperor Qianlong in China. The investigation revealed that the engravings and iconographies of the tomb were arranged in order to reflect the Buddhist Tibetan funerary ritual; their layout and spatial position

reflects the inscription of religious texts within a stupa. To visually show this kind of relationship a virtual stupa was created and put in relationships with the final 3D model in order to allow the interlinking between spatial and conceptual elements.

A very interesting approach is CultureSampo, the Finnish semantic web portal for memory institutions, which hosts records about artefacts, narrative, music, craftsmanship and other (Mäkelä et al., 2012; Ruotsalo et al., 2006). The content are documented using the FinnONTO ontology, which allow the interrelationship between records about intangible heritage, usually in the form of annotated video, and about material objects. This remarkable work it would be perfect if only the agency of the activity, together with the symbolism implicit in the interpretation of an artefact, would be taken in consideration. It still remains, however, the best example of data integration and harmonisation in cultural heritage.

From the above examples seems that so far the researchers have avoided developing a theoretical framework of application, which would allow them to explain what they need to document.

\section{Methodological foundation for a documentation framework}

\subsection{Requirements}

In order to understand the complexity of our proposal from Section 2 it is important to present a general framework that examines the possibility of documenting different assertions and representations of the object of our discourse. We are going to use the example of a Byzantine wall painting for transcending the dichotomy materialperformance, providing a clarification of the different requirements for recording the tangible/intangible elements of a specific object.

Following Section 2.0, it is important to underline that the framework used for the documentation needs to take into account the particular architecture of the self-other-object relationships. For this reason, it is crucial to stress the importance of the agent in the conceptualisation and production process. A framework of analysis should give account to the sign object, with the concept it symbolise, and the thing it refers to, under the constraint of a context-dependent action in an universe of symbolical and collective representations (Fig. 1).

In the case of Byzantine icons, such a system is determined by the artistic and iconographic production and their function within the religious space (comprehensive therefore of activities and literature production) (Falkenberg et al., 1998; Jovchelovitch, 2007; Staab and Studer, 2009).

In order to achieve this goal, we need to encode the various assertions throughout an ontology, using different semantic spaces and properties to formalise the relationships between those elements. This approach will help differentiating the propositions that refer to a physical object from the meaning assigned to them by an interpreter. Moreover, while dealing with digital data, we should make sure to formalise their relationship to the object depicted, in order to use property propagation (Wickett et al., 2010) for better retrieval and categorisation of the results. As an example, Fig. 2 shows how we can use a semantic system for inferring implicit knowledge from current records, automatically linking the digital representations with some conceptual elements, or with some events, in order to recreate the context of depiction, use, and comprehension of an object.

For achieving such result, it is necessary to encode the information

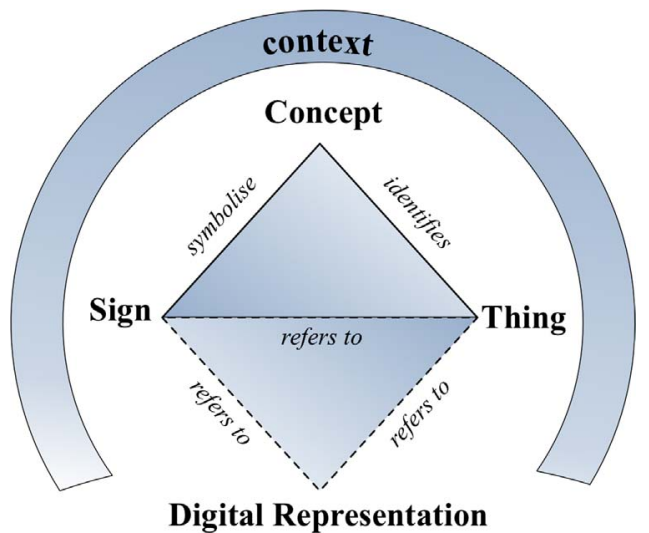

Fig. 1. Semiotic triangle developed from Staab and Studer (2009). 


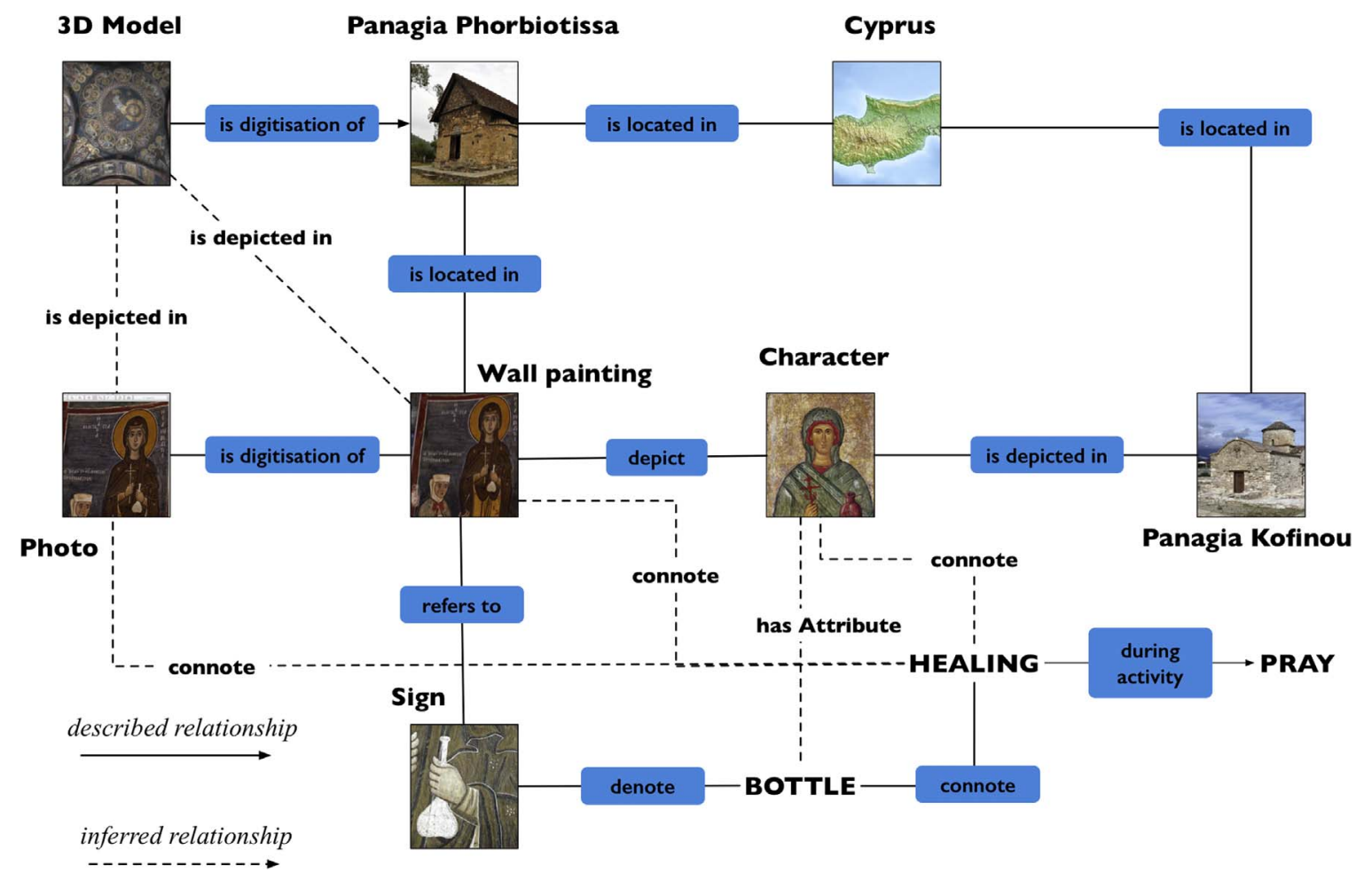

Fig. 2. Property propagation.

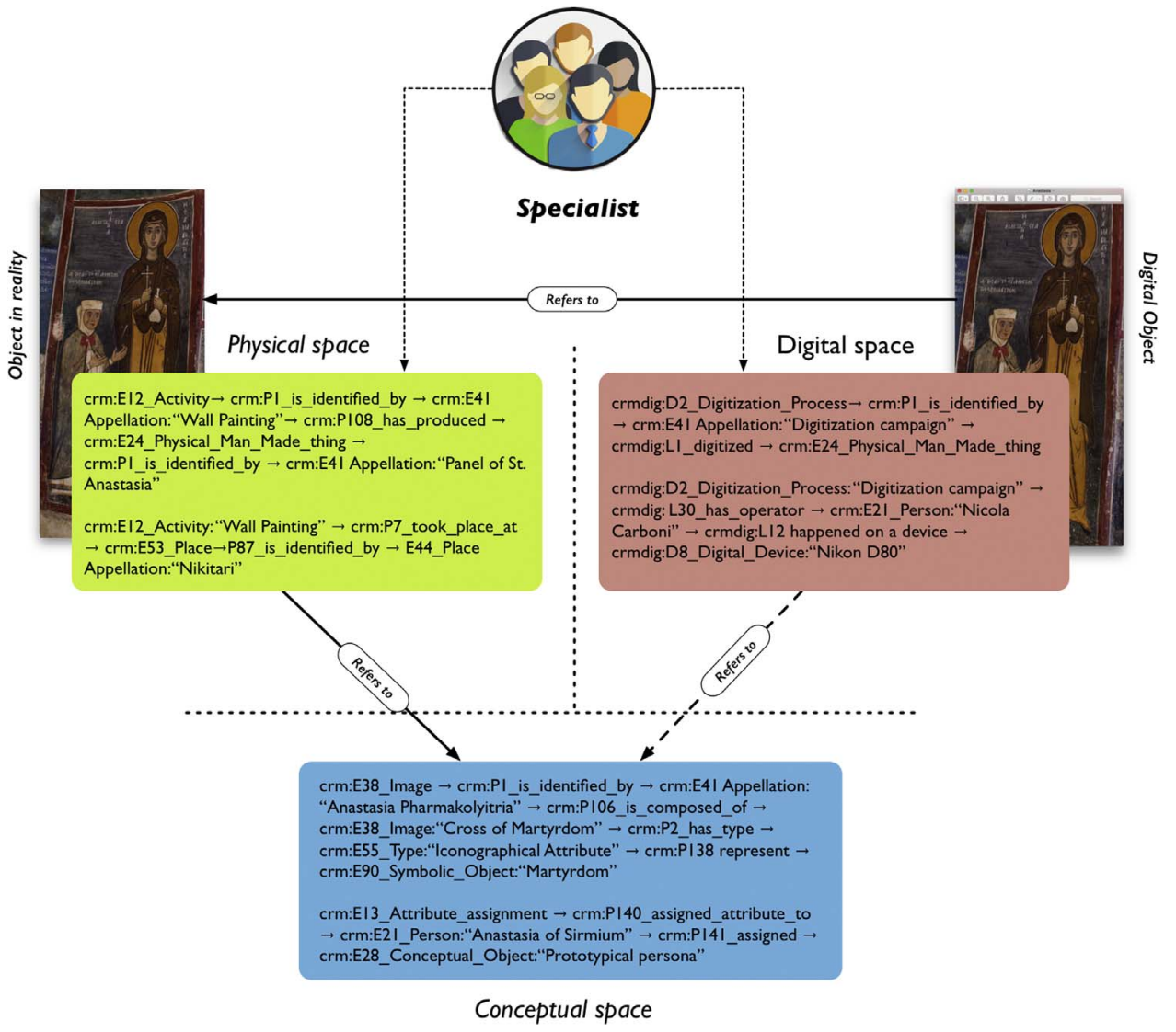

Fig. 3. Information spaces.

about the physicality of the wall painting in a separate semantic space than the one of its digital forms, and link them together to a conceptual space which carry the meaning assigned to them (Fig. 3). Such separation helps the registration of different interpretations related to the same object.

In order to fulfil this requirement, we should opt for an information structure that follow the "Open World Assumption", which states that the information recorded is not complete, since the facts described 
Table 1

Queries.

\begin{tabular}{ll}
\hline ID & Queries \\
\hline $\mathbf{1}$ & Find all the images about Anastasia Pharmakolyitria \\
$\mathbf{2}$ & Find all the iconographical attributes of the icon of St. Anastasia \\
$\mathbf{3}$ & Find all the icons of St. Anastasia in Cyprus \\
$\mathbf{4}$ & Find objects used during the activity "praying" \\
$\mathbf{5}$ & Find all the objects that influenced the activity "praying" \\
\hline
\end{tabular}

cannot fully represent the whole knowledge available in a field (Sowa, 2000).

In order to test the above requirements, we decided to use CIDOCCRM (Doerr, 2003; Le Bœuf et al., 2015) as our reference ontology. CIDOC-CRM is an empirically developed and non-prescriptive ontology focused on the cultural heritage domain. It is organised into class and relationships, and it will allow us to show how the entities in the world, of different nature, are strongly interconnected. An advantage of CIDOC CRM is further, that it gives its users the possibility to expand it with extensions and to use different modules, which have been already developed, such as CRMGeo (Doerr and Hiebel, 2013) for the description of spatial information and FRBRoo (Bekiari et al., 2015) for the documentation of bibliographic information.

In order to guide our examination and demonstrate the potentiality of CIDOC-CRM to record the tangible/intangible aspects of the heritage we prepared a set of test queries (Table 1) that we set as the goal to be able to answer through a semantic structure in the next pages.

\subsection{Analysis}

The following analysis will take into account the theoretical paradigm expressed in Section 2, and will test the requirements for a comprehensive description of the conceptual and physical characteristic of cultural object, using as a case study a Byzantine icon from the church of Panagia Phorbiotissa/Asinou, a UNESCO World Heritage Site in the Troodos mountains of Cyprus. The examined fresco (Fig. 4) is part of the late 13th century cycle of painting, and it is situated on the wall of the south apse of the narthex, depicting St. Anastasia Pharmakolyitria holding a white martyr cross and a white bottle. She is commonly described with the epithet "dissolver of potion", and the overall figure is iconographically linked to the concept of healing (Carr and Nicolaïdès, 2012).

\subsubsection{Wall painting}

The sets of information regarding the production of the panel of Anastasia are semantically described using CIDOC-CRM and CRMGeo (Fig. 5) as an information framework, with Carr and Nicolaïdès (2012) as main literary source, and presented in Fig. 6 in the form of a graph. The basic elements for the description of a physical object, starting from its temporal and spatial property, are included together with the information in regards of the agency, the author's membership to an artistic group and the technique used, along with the requirements in terms of materials and tools. In the model we defined the specific spatial region of the wall painting (Fig. 9), in order to link its materiality with the image (conceptual element) depicted.

\subsubsection{Digital data}

Fig. 7 outlines a schema for recording the provenance information of a digital object, answering the questions of who made the photo, how s/ he did it, when s/he did it and what it depicts. We can easily record that the digitization event digitizes one specific part of the wall painting for the purpose of documenting it (specifically Fig. 9), therefore the photo has to be seen as primary document for the fresco of St. Anastasia. It is also very important to highlight the possibility to use

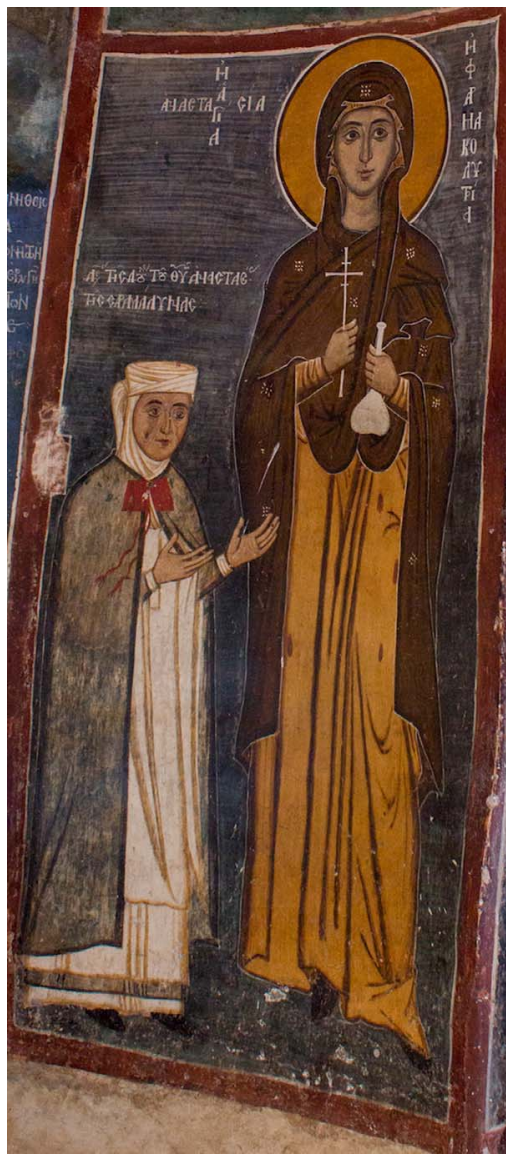

Fig. 4. Anastasia \& Anastasia panel.

property propagation for transferring the height information present in an annotation to the photo to the actual entity which represent the wall painting, enriching our information system with new implicit knowledge (Tzompanaki et al., 2013).

\subsubsection{Image symbolism}

In Fig. 7 we defined the spatial region of the wall painting, and the image associated with it, linking the materiality of the depiction with its identity, which is a cultural-dependent property. Fig. 8 continues to explore this dimension, outlining the symbolic content of the pictorial representation, in this case, the one of Anastasia Pharmakolyitria (Fig. 9). The recognition of the iconographical object relies on a set of attributes and characteristics that reveals its identity to the researcher, who is now able to place the icon within its context (religious system), where it has a clear function.

The iconographical description should also consider the symbolism and abstraction used by the artist. That is why we need to distinguish between elements that represent personifications as well as allegories and attributes (van Straten, 1994). The differentiation of these concepts helps to automatically categorise and retrieve the characters depicted, as well as the symbolic meaning given to certain objects. What is more, it allows us to better comprehend the habitus of the producer and receiver by unveiling the conceptualisation of the sign object by an agent within a contextual space, as required in Section 4.1.

Additionally, this step shows how it is possible to relate an image within a specific system of representations, allowing a reprojection/ comparison of the symbolic characteristic attributed to a specific fictional character, and helping study the evolution of the conventions behind the depiction of works of art. The historical influence together with the use of different iconographical elements in the depiction of certain characters, can unveil the variations in the schemas and 

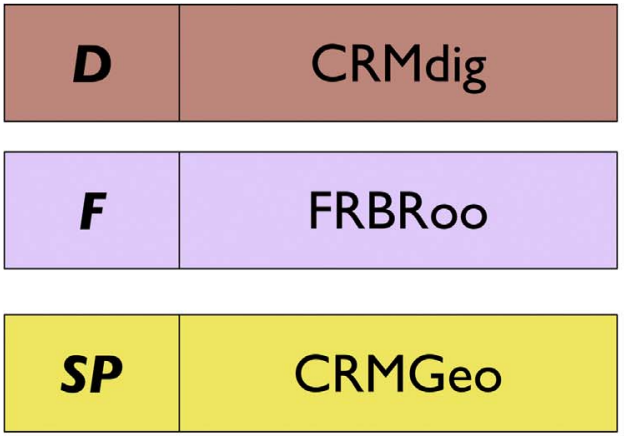

E CIDOC-CRM

\section{Dig propriety}

FRBRoo propriety

Geo propriety

Fig. 5. CRM Legend.

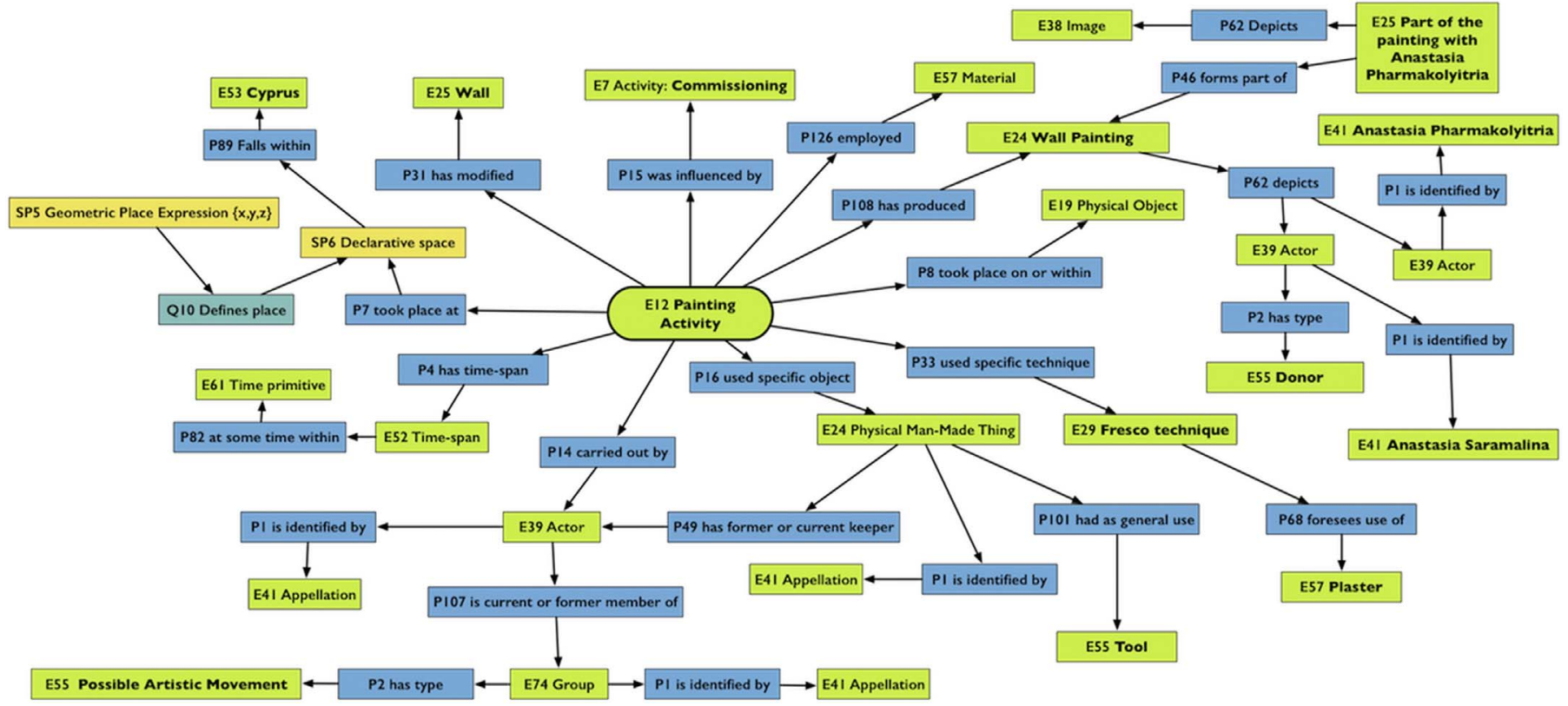

Fig. 6. Wall painting description.

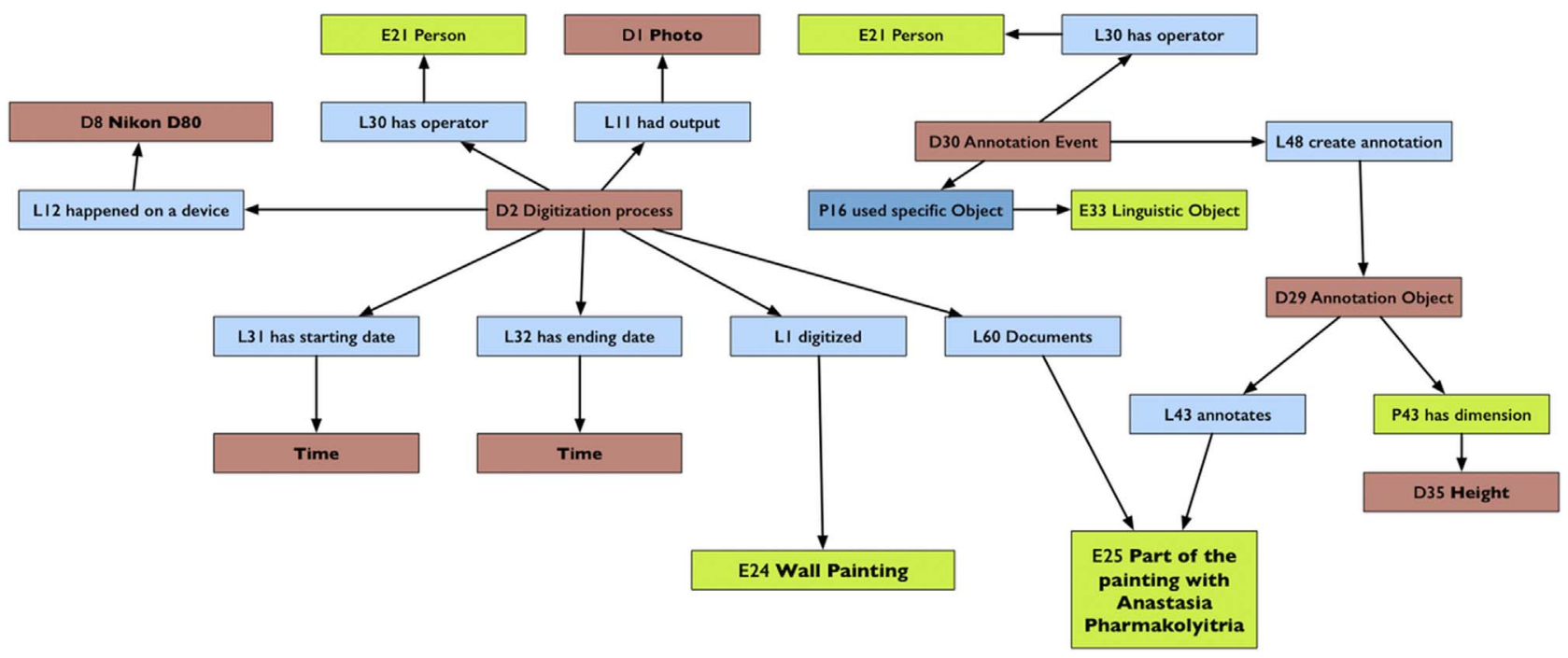

Fig. 7. Digital data description. 


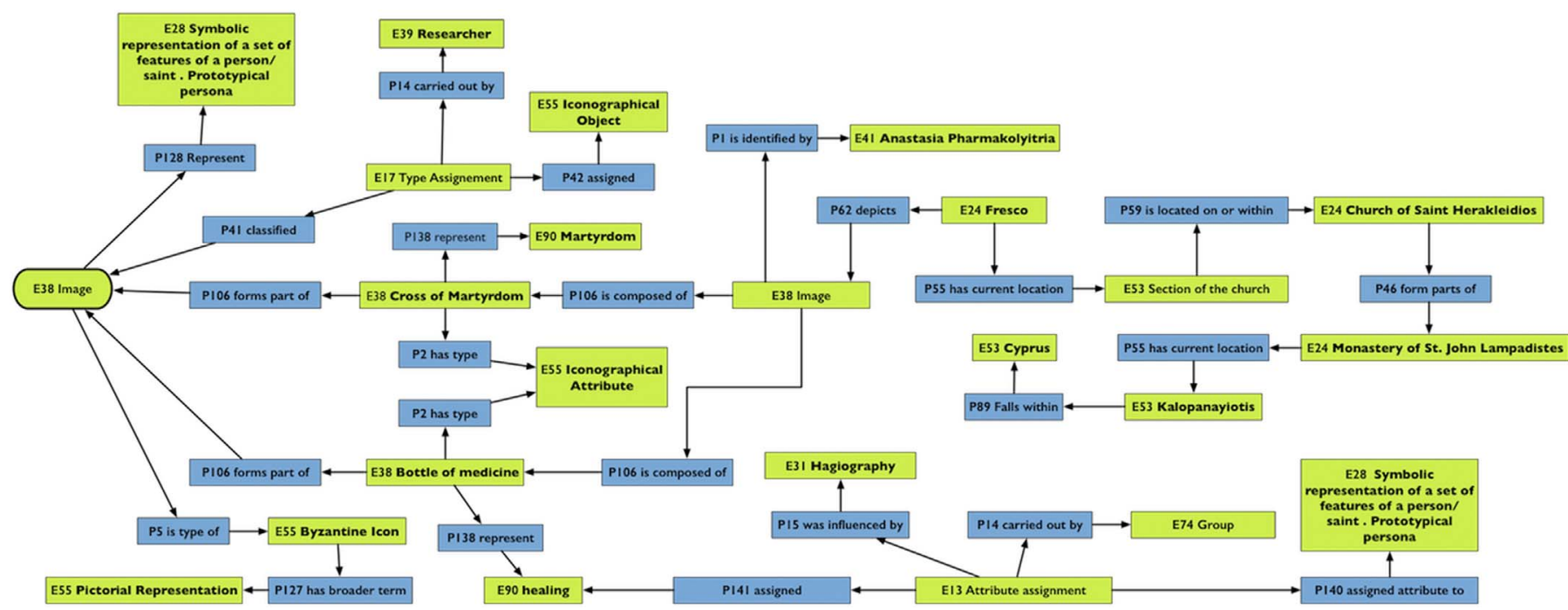

Fig. 8. - Image description in CRM.

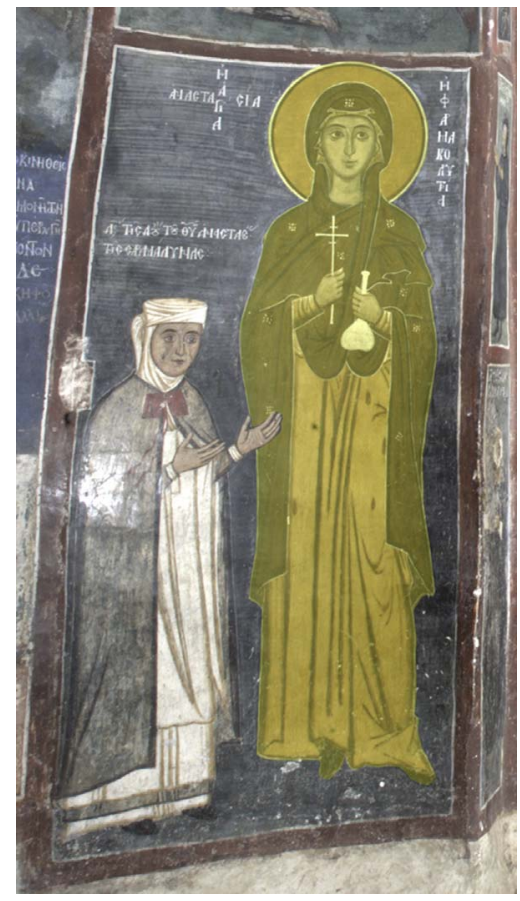

Fig. 9. Anastasia Pharmakolyitria.

dictionaries used for depicting the same subject, highlighting moreover the influences in the stylistic evolutions of an icon.

In this stage, we can also describe the assignment of a symbolic element as a process carried out by a collective agency that uses some normative system or belief; we use the example of the hagiography of the saint, for assigning a status to a certain object.

At this level, it is already possible to see how some 'intangible' elements are recorded and projected within the tangible object. The description of the set of symbols, in fact, has to be always considered an interpretation of a situation where an ethnographer or a historian gives us an account of a social discourse (Geertz, 1973). The recording of this social discourse, which would allow us to interpret and give meaning to a specific setting, is nothing more than a series of attributes identified as 'intangible heritage'.

Coming back to the queries in Table 1, thanks to the data described at this step, we would be able to answer the first three queries. The first one is going to provide the user with all the images of St Anastasia. The second query would list both the cross and the bottle of medicine as typical characteristics which identify St. Anastasia. The third query would provide the reference to both the church of Panagia Phorbiotissa in Asinou and the Monastery of St. John Lampadistes.

\subsubsection{Object, performance, symbols}

Here we argue that the link between an icon and a person is not direct, but takes into account only a certain set of features of the person, creating a symbolic version that here we call "prototypical persona". The icon refers always to the symbol of the person, not to the person themselves. Consequently, the prayers towards Anastasia Pharmakolyitria are directed towards the concept of her, not towards the person that died centuries ago. That is why we associate the diverse liturgical activities involving a saint not to the original person, but to its persona.

In order to document the construction of meaning in relation to a saint, we can record the motivations throughout the documentation of an attribute assignment. In the case of Fig. 10, we use both, the hagiography and the prayers used to invoke the saint. Both are responsible for the immaterial characteristic of that persona, who is seen as a healer, and depicted as such too, thanks to those sources. The activity of praying is described as a performance, which use a specific prayer, described both in its conceptual and in its material form (related to other liturgical sources), to refer to the persona of the saint. St Anastasia is represented as main influencer of the activity as well as the subject of the specific prayer used during the performance. Both the motivation (be healthier) and the purpose of the performance is recorded, together with the relation between the performance and the material anchor used for the activity (the panel of St. Anastasia).

In order to express the connection between the documentation of the performance (a photo), the performance itself, and the material anchor used, we described a recording event, which document both the performance and the physical object depicted in the photo (the panel of St. Anastasia).

If, in this case, the description works at a functional level, successfully associating the concept of healing with the praying towards a certain saint, it still not fully sufficient for capturing the agency and intentionality of the act. Nevertheless, it suffices to create the triad event-object-concept that, as argued above, would form the proper ground for the retrieval, organisation and analysis of the tangible and intangible heritage information, following the requirements outlined in Section 4.1. 


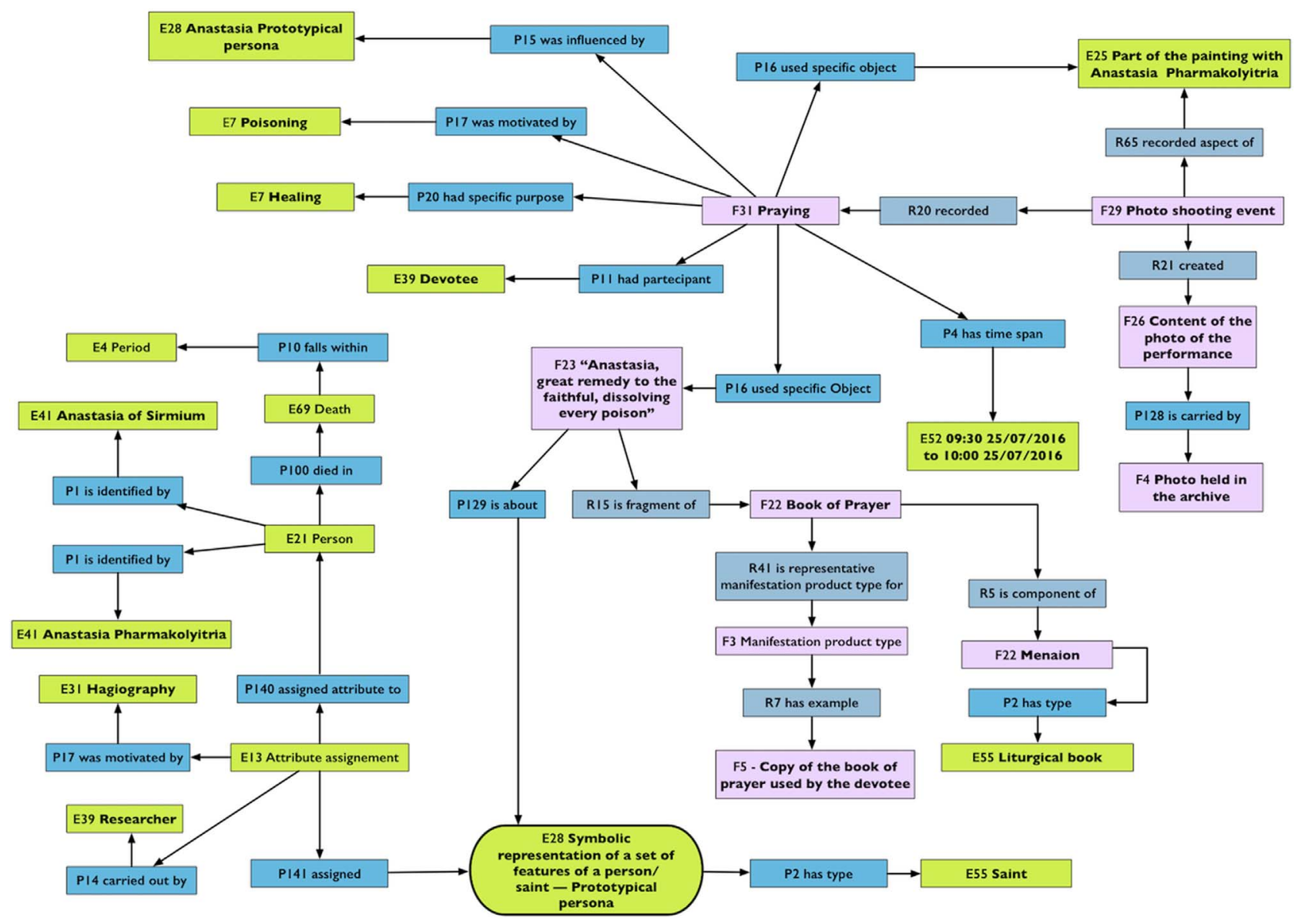

Fig. 10. Contextual description in CRM.

Table 2

Paradigm.

\begin{tabular}{|c|c|c|}
\hline Subject & Tangible aspects & Intangible aspects \\
\hline Technique & $\begin{array}{l}\text { The procedure used it is important not only for the technological } \\
\text { capabilities, but also for highlighting the social constraints and } \\
\text { interactions during a production event. }\end{array}$ & $\begin{array}{l}\text { The procedure define the execution. It is significant for the comparison of the } \\
\text { discrete actions, as well as for their association with the conceptual knowledge } \\
\text { necessary for their comprehension. }\end{array}$ \\
\hline Spatial/temporal & Valuable for the origin, use and storage of material objects. & $\begin{array}{l}\text { Salient for the recurrences of a practice in time/space and the definition of its } \\
\text { influences/aims. }\end{array}$ \\
\hline Activity & $\begin{array}{l}\text { The participation/influence during an activity relate it to the } \\
\text { performance and the agency. }\end{array}$ & The parthood relationship between itself and other activity/event. \\
\hline Object & The parthood relationship between itself and other object & $\begin{array}{l}\text { Its description help create patterns of practices which used for the same } \\
\text { function/agency some specific tools. }\end{array}$ \\
\hline Material & Important for its composition, origin/provenance. & $\begin{array}{l}\text { Import for postulating the significance pre-practice or post-practice, and for } \\
\text { aggregating similar performances. }\end{array}$ \\
\hline Agent/Agency & \multirow{2}{*}{\multicolumn{2}{|c|}{$\begin{array}{l}\text { Essential to record the agent (or a social group) who carry out an act, the purpose/motivation of the act and connect it with a possible results. } \\
\text { It helps unravel similarities and commonalities between social groups (intended meaning of an object for an actor, or the symbolic function of a pose within } \\
\text { a performance). }\end{array}$}} \\
\hline Symbolism & & \\
\hline
\end{tabular}

\subsection{Paradigm}

The above analysis helped us define seven dimensions (Table 2), that together with the requirements in Section 4.1 (using a shared ontology, registration in different semantic spaces, interrelation of symbolic and physical attributes, the "open world assumption"), help record the tangible and intangible elements of an heritage asset. Recording these dimensions during the documentation practice would help, as show by the several examples in Section 4.2, to relate relate performative activities with material objects, moreover, recording how the two influence each other.

We are aware that the formulation of prescriptive recipes limit the discourse of the documentalist, but here it has to be seen as less harmful in respect to a fragmentation of the heritage in two unnatural domains. Moreover, the use of the suggested formula would only regards the suggested interconnections between diverse heritage aspects, leaving to the documentalist the freedom of choosing its own methodology for their formalisation.

We, therefore, argue that the formula outlined in Table 2 would help researchers discover similarities and shared practices between social groups, as well as better comprehend intracultural variations and the significance of certain acts or objects in the daily practice.

\section{Conclusions}

In the above article we showed how a cultural object has multiple 
facets and dimensions that incorporate both tangible and intangible elements. Using pictorial representation as an example we proposed a protocol for highlight such features in a semantic system.

The proposed approach allowed us to describe a set of intangible elements on the base of a production event, the symbolism used, and the relations with a performative event, together with the stylistical features, the technological system used for the construction of a cultural object, while providing the possibility to describe a partial view of the habitus of production and use of heritage object.

However, even if the answer to the queries were successfully achieved we feel that there is a need for better developing certain features, providing a more stable semantic structure for the description of symbolic relationships, as well as recording events or the character of social groups.

\section{Acknowledgements}

The authors would like to extend their gratitude to George Bruseker, FORTH, for his insights and comments on the paper.

This project has received funding from the European Union's Seventh Framework Programme for research, technological development and demonstration under Grant agreement no 608013.

\section{References}

Amin, R., Baker, O.F., Deraman, A., Yatim, N.F.M., 2012. Transforming Model to Meta Model for Knowledge Repository of Malay Intangible Culture Heritage of Malaysia. Int.

J. Electr. Comput. Eng. 2, 231-238. http://dx.doi.org/10.11591/ijece.v2i2.205. Amin, R., Yatim, N.F., Deraman, A., Baker, O.F., 2011. Repository Model for Intangible

Heritage "The Malay Scenario," in: Presented at the International Conference on Advanced Science, Engineering and Information Technology, pp. 227-231. 〈http://dx.doi.org/10.18517/ijaseit.1.2.47http://dx.doi.org/10.18517/ ijaseit.1.2.47), 227-231

Baca, M., Harpring, P., Lanzi, E., McRae, L., Whiteside, A., 2006. Cataloging Cultural Objects. American Library Association. 〈http://dx.doi.org/10.1016/j.lcats.2007.07. $011\rangle$

Bal, M., Bryson, N., 1991. Semiotics and art history. Art. Bull. 73, 174. http://dx.doi.org/ $10.2307 / 3045790$.

Bekiari, C., Doerr, M., Le Bœuf, P., Riva, P., 2015. FRBR object-oriented definition and mapping from FRBRER. FRAD and FRSAD.

Bouchenaki, M., 2003. The Interdependency of the Tangible and Intangible Cultural Heritage. ICOMOS Special Collection Volume 14, pp. 1-5

Carr, A.W., Nicolaïdès, A., 2012. Asinou Across Time. Dumbarton Oaks Research Library and Collection, Washington, D.C.

De Luca, L., De Domenico, F., Lombardo, J., Stefani, C., Pierrot-Deseilligny, M., Wang, F., 2013. When script engravings reveal a semantic link between the conceptual and the spatial dimensions of a monument: the case of the tomb of Emperor Qianlong, in: Presented at the Digital Heritage International Congress, IEEE, pp. 505-512. 〈http://dx.doi.org/10.1109/DigitalHeritage.2013.6743790〉

Doerr, M., 2003. The CIDOC conceptual reference module: an ontological approach to semantic interoperability of metadata. AI Mag. 24, 75-92. http://dx.doi.org/ 10.1609/aimag.v24i3.1720.

Doerr, M., Hiebel, G., 2013. CRMgeo: Linking the CIDOC CRM to GeoSPARQL through a Spatiotemporal Refinement. ICS-FORTH

Falkenberg, E.D., Hesse, W., Lindgreen, P., Nilsson, B.E., Oei, J.L.H., Rolland, C., Stamper, R.K., Van Assche, F.J.M., Verrijn-Stuart, A.A., Voss, K., 1998. A Framework of Information System Concepts. International Federation for Information Processing.

Fauconnier, G., Turner, M., 2003. The Way We Think. Basic Books, New York. Geertz, C., 1973. The Interpretation of Cultures. Basic

Gombrich, E.H., 1994. The Image and the Eye. Phaidon Press, London.

Grenfell, M., 2008. Pierre Bourdieu. Acumen, Durham, UK.

Guarino, N., 1998. Formal ontology in information systems. In: Presented at the Formal Ontology in Information Systems, Amsterdam, Washington, DC, IOS Press, Tokyo,
Omsha.

Hodder, I., 2012. Entangled. John Wiley \& Sons, Chirchester, UK, Maldem, USA. Hu, J., Lv, Y., Zhang, M., 2014. The ontology design of intangible cultural heritage based on CIDOC CRM. Int. J. u- and e- Serv. Sci. Technol. 7, 261-274. http://dx.doi.org/ 10.14257/ijunesst.2014.7.1.24.

Hutchins, E., 2005. Material anchors for conceptual blends. J. Pragmat. 37, 1555-1577. http://dx.doi.org/10.1016/j.pragma.2004.06.008.

Istituto Centrale per il Catalogo E La Documentazione, 2006. SCHEDA BDI Beni demoetnoantropologici immateriali. Istituto Centrale Per Il Catalogo E La Documentazione, Roma, Italy.

Ito, N., 2003. Intangible cultural heritage involved in tangible cultural heritage. In: Presented at the ICOMOS General Assembly and International Symposium, Victoria Falls, Zimbabwe.

Jovchelovitch, S., 2007. Knowledge in Context. Routledge, London \& New York.

Kettula, S., Hyvönen, E., 2012. Process-centric cataloguing of intangible cultural heritage. In: Presented at the CIDOC.

Kim, S., Kim, Y., 2013. A study on the development of metadata elements for intangible cultural heritage records based on FRBR. J. Korean Soc. Inf. Manag. 30, 119-141. http://dx.doi.org/10.3743/KOSIM.2013.30.2.119.

Kirshenblatt Gimblett, B., 2004. Intangible heritage as metacultural production. Mus. Int 56, 52-65. http://dx.doi.org/10.1111/j.1350-0775.2004.00458.x.

Kurin, R., 2004. Safeguarding intangible cultural heritage in the 2003 UNESCO convention: a critical appraisal. Mus. Int. 56, 66-77. http://dx.doi.org/10.1111/ j.1350-0775.2004.00459.x.

Le Bœuf, P., Doerr, M., Ore, C.E., Stead, S., 2015. CIDOC Conceptual Reference Model. Lemonnier, P., 2013. De l'immatériel dans le matériel... et réciproquement! techniques et communication non verbale. J. Soc. Océanistes, 15-26. http://dx.doi.org/10.4000/ jso.6959.

Lemonnier, P., 2012. Mundane Objects: Materiality and Non-verbal Communication. Left Coast Press, Walnut Creek, California.

Lubas, R., Jackson, A., Schneider, I., 2013. The Metadata Manual. Elsevier, Oxford, UK.

Mallik, A., Chaudhury, S., Dinesh, T.B., 2013. An intellectual journey in history: preserving indian cultural heritage. In: Presented at the New Trends in Image Analysis and Processing-ICIAP, Springer, 2013, pp. 298-307.

Mallik, A., Chaudhury, S., Ghosh, H., 2011. Nrityakosha: preserving the intangible heritage of Indian classical dance. J. Comput. Cult. Herit. 4, 298. http://dx.doi.org/ 10.1145/0000000.0000000.

Mauss, M., 1973. Techniques of the body. Econ. Soc. 2, 70-88. http://dx.doi.org/ $10.1080 / 03085147300000003$.

Mäkelä, E., Hyvönen, E., Ruotsalo, T., 2012. How to deal with massively heterogeneous cultural heritage data-lessons learned in CultureSampo. Semant. Web 3. http:// dx.doi.org/10.3233/SW-2012-0049.

Miller, D., 2010. Stuff. Polity Press.

Miller, D., 2005. Materiality. Duke University Press Books.

Propp, V., 1971. Morphology of the Folktale. University of Texas Press.

Ruotsalo, T., Häggström, T., Mirva, S., Junnila, M., Virkkila, M., Haaramo, M., Makela, E., Kauppinen, T., Viljanen, K., 2006. Culturesampo-finnish culture on the semantic web: The vision and first results. In: Presented at the Finnish Artificial Intelligence Conference STeP.

Sowa, J.F., 2000. Knowledge Representation. Brooks/Cole.

Staab, S., Studer, R., 2009. Handbook on Ontologies. Springer Berlin Heidelberg, Berlin, Heidelberg. http://dx.doi.org/10.1007/978-3-540-92673-3.

Tan, G., Hao, T., Zhong, Z., 2008. A knowledge modeling framework for intangible cultural heritage based on ontology. In: Presented at the Knowledge Acquisition and

Modeling. pp. 304-307. 〈http://dx.doi.org/10.1109/KAM.2009.17〉

Taylor, D., 2003. The Archive and the Repertoire. Duke University Press. http:// dx.doi.org/10.1215/9780822385318.

Tzompanaki, K., Doerr, M., Theodoridou, M., 2013. Reasoning based on property propagation on CIDOC-CRM and CRMdig based repositories. In: Presented at the International Conference on Theory and Practice of Digital Libraries.

UNESCO, 2006. Masterpieces of the Oral and Intangible Heritage of Humanity.

UNESCO, 2003. Convention for the Safeguarding of the Intangible Cultural Heritage.

Uther, H.-J., 2004. The Types of International Folktales. A Classification and Bibliography. Based on the System of Antti Aarne and Stith Thompson. Academia Scientiarum Fennica.

van Straten, R., 1994. An Introduction to Iconography. Taylor \& Francis, London \& New York.

Viudez, M.C., 2010. Metodologia de recerca etnològica. Generalitat de Catalunya Generalitat de Catalunya. Departament de Cultura i Mitjans de Cominicació.

Wickett, K.M., Renear, A.H., Urban, R.J., 2010. Rule categories for collection/item metadata relationships. Proc. Assoc. Inf. Sci. Technol. 47, 1-10. http://dx.doi.org/ 10.1002/meet.14504701218. 